\title{
The Red Blood Cell and Nitric Oxide: Derived, Stimulated, or Both?
}

\author{
Stephen T. Halpin, Kari B. Anderson, Paul A. Vogel and Dana M. Spence*
}

Department of Chemistry, Michigan State University, East Lansing, MI 48824

\begin{abstract}
Following a brief introduction to properties of the red blood cell (RBC), this review will provide information pertaining to the role of the RBC as both a deliverer of nitric oxide (NO), and a stimulator of NO release via RBCgenerated ATP. In addition, an evaluation of the potential downstream effects of RBC-derived ATP, via its ability to stimulate NO in other cell types, will be provided. Collectively, it is now apparent that the RBC is a determinant in functions other than oxygen delivery alone.
\end{abstract}

Keywords: Nitric oxide, adenosine triphosphate, red blood cell, endothelial cells, platelets, vasodilation, hypoxia, transendothelium electrical resistance (TEER), microfluidic technology.

\section{INTRODUCTION}

The average human red blood cell (RBC) has a volume of approximately 87 femtoliters, is about 6-7 $\mu \mathrm{m}$ in diameter, and spends, on average 110-120 days in the human body before being metabolized by such organs as the spleen. RBCs also represent about $40-45 \%$ of the total blood volume in an adult human $(5 \mathrm{~L})$; thus, the average adult has about 2 $\mathrm{L}$ of RBCs. The RBC also has many unique features in comparison to other cell types in vivo in that it lacks a nucleus and has no mitochondria. However, the RBC is not completely void of cell machinery; indeed, it has a very active cell bilayer, possesses a glucose transporter (GLUT1), has many of the same ion pumps as other cells, and is even thought to participate in the overall control of blood flow.

While the classical role of the RBC in vivo is to supply oxygen to demanding tissues and organs, it is now clear that the RBC itself participates in overall blood flow and, as such, increases the number of oxygen-carrying cells to the hypoxic tissue. Unfortunately, the mechanism by which the $\mathrm{RBC}$ facilitates blood flow is not unified, although the competing mechanisms that do exist have commonalities. In this review, the RBC's role as a participant in vasoregulation will be examined from two points of view; first, as a direct deliverer of $\mathrm{NO}$ and a stimulator of NO-release via $\mathrm{RBC}$ generated ATP.

\section{NITRIC OXIDE AS A VASOACTIVE MOLECULE AND DELIVERY BY THE RBC}

Since the recognition of an endothelium derived relaxation factor (EDRF) [1] and subsequent identification as NO $[2,3]$, and the Nobel Prize in Physiology or Medicine in 1998, there has been some debate as to the physiological origin of vasoactive NO under hypoxic conditions. There are three general sources considered, two of which originate in the RBC: that as $S$-nitrosothiols from hemoglobin, and NO produced through nitrite reductase activity of hemoglobin. A

*Address correspondence to this author at the Department of Chemistry, Michigan State University, East Lansing, MI 48824; Tel: 517355 9515; Ext: 174: E-mail: dspence@chemistry.msu.edu further described potential mechanism is that of ATP induced NO production in the endothelium, through eNOS. These mechanisms are described pictorially in Fig. (1).

\section{S-Nitrosothiols as Vasoactive NO}

Stamler et al report that NO is carried in a stable form as a $S$-nitrosothiol at a highly conserved cysteine residue on the beta strand of hemoglobin $[4,5]$. The vasoactivity of this NO species is then maintained and protected from the surrounding chemical environment in a more stable form. This is an important consideration as in the RBC and whole blood, there are many chemical species including heme, oxygen and small molecule thiols that can react with NO, eliminating its vasoactivity. While it has been shown the half-life of NO may be dependent on oxygen saturation [6], it is often estimated to be less than a few seconds [7, 8]; therefore a theory that presents a more stable form of $\mathrm{NO}$, which would be more likely to reach the smooth muscle, is favorable. Furthermore, the formation of $S$-nitrosothiols is favorable at high oxygen saturations, and the release more favorable as the hemoglobin changes configuration at low oxygen saturations, offers a mechanism for release under hypoxic conditions $[4,9]$.

\section{Nitrite Reductase Activity of Hemoglobin}

Alternatively, other work provides evidence that the bioavaliable source of $\mathrm{NO}$ is through the nitrite reductase activity of hemoglobin, first investigated in the early 80 's [10]. Much like the nitrosothiols mentioned above, nitrite is also proposed to be a stable form of storage for $\mathrm{NO}$, and is present in the plasma at concentrations between 500 and $1000 \mathrm{nM}$ [11]. A significant piece of supporting information for this hypothesis is an observable concentration gradient for nitrite between arterial and venous blood [11, 12]. While leaving questions to the specific mechanisms, this decrease in concentration as the blood is deoxygenated indicates the nitrite is being consumed, perhaps in the formation of $\mathrm{NO}$ [13]. Furthermore, in this study, an increase in blood flow is observed with the infusion of nitrite in vivo. While the authors acknowledge the challenges in NO escaping reaction with hemoglobin, it is known that the nitrite reductase 


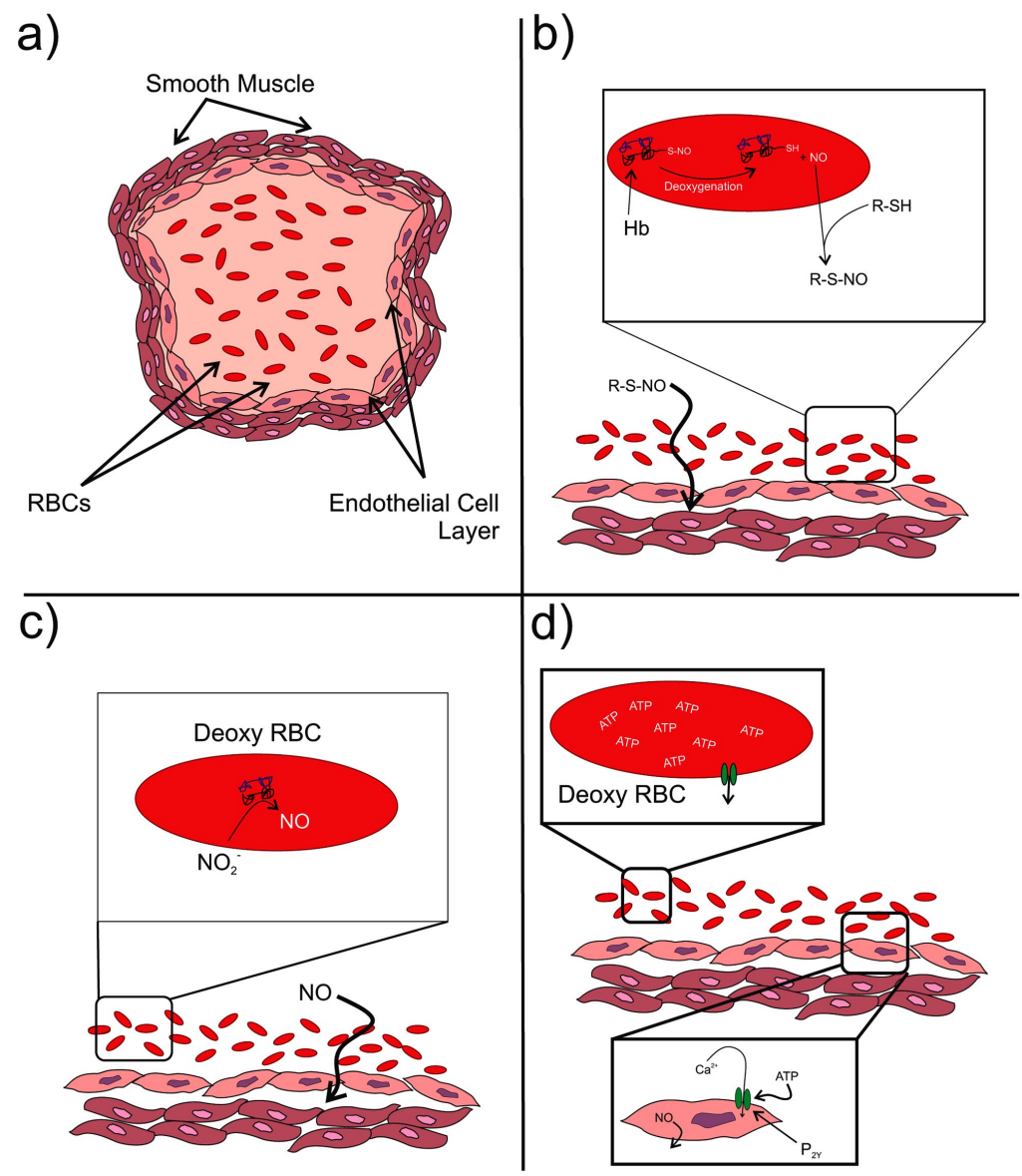

Fig. (1). Summary of Proposed Mechanisms for RBC Mediated Vasodilation: Shown in panel (a) is a typical blood vessel cross section. The center of this cross section contains the RBCs, plasma, and other blood components. The inner layer of the vessel wall consists of the endothelial cells, which are surrounded by the smooth muscle. The remaining panels are cross sections of (a). Shown in (b) is a pictorial representation of the SNO-Hb mechanism in which cysteine bound $\mathrm{NO}$ is released when $\mathrm{Hb}$ changes to the deoxygenated configuration. NO is then able to diffuse out of the cell, where it reacts with a free thiol species, such as glutathione or albumin. This species then carries it to the vessel wall where it must diffuse to the smooth muscle to induce vasodilation. Panel (c) summarizes the mechanism considering Hb as a nitrite reductase. In this case, nitrite diffuses into the RBC where deoxygenated $\mathrm{Hb}$ can act as a nitrite reductase, producing NO. This NO can then diffuse through the endothelium, to the smooth muscle, inducing vasodilation. Finally, in panel (d), the ATP mediated mechanism is summarized. ATP is actively released under hypoxic conditions, and then diffuses to the endothelium where it interacts with the P2Y receptor, inducing calcium flux into the cell. This activates eNOS, producing NO, which can then diffuse out of the cell and to the smooth muscle.

activity of hemoglobin is only seen in the deoxygenated state [10], offering a control mechanism for NO production.

\section{STIMULATION OF NITRIC OXIDE BY THE RELEASE OF ATP FROM THE RBC}

\section{ATP and the Purinergic Receptors}

Indeed, the application of ATP to endothelial cells results in increases in NO synthesis $[14,15]$. ATP is of particular interest because it is present in millimolar amounts in RBCs [16-19]. Multiple receptors for ATP have been identified and partially characterized [14, 20-23]. In the vasculature, the $\mathrm{P} 2 \mathrm{x}$ purinergic receptor is present primarily on vascular smooth muscle cells and its activation results in contraction of that cell $[21,24,25]$. In contrast, the $\mathrm{P} 2 \mathrm{y}$ receptor is found primarily on the endothelium [14, 20, 22, 24]. The binding of ATP to the endothelial P2y receptor results in the synthesis of NO $[14,16]$ and/or vasodilator arachidonic acid metabolites [26, 27]. Thus, ATP applied directly to the vascular smooth muscle of an intact vessel, e.g., that are released from nerve terminals, would be expected to produce vasoconstriction via activation of $\mathrm{P} 2 \mathrm{x}$ receptors. In contrast, ATP applied to the luminal side of a vessel, e.g. that released within the circulation from RBCs, would be expected to produce endothelium-dependent vasodilation through interaction with the $\mathrm{P} 2 \mathrm{y}$ receptor present on the endothelial cell and the subsequent release of NO [14, 25].

\section{ATP Stimulation of NO in the Endothelium}

Our group [28], along with others, have shown that when exposed to a hypoxic environment, RBCs release as high as $2 \mu \mathrm{M}$ ATP, and that this ATP is able to activate eNOS [16, 29, 30]. Furthermore, upon reaching the endothelium, it is known this ATP can activate eNOS though $\mathrm{P} 2 \mathrm{y}$ receptors 


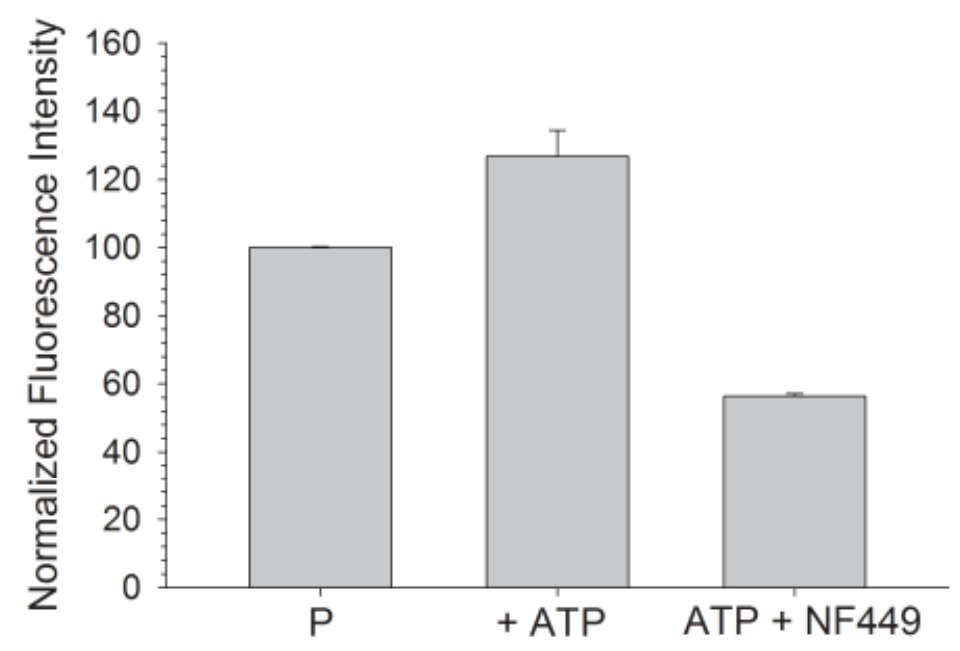

Fig. (2). Platelet NO production after the addition of ATP. The basal NO levels in the platelet were measured with a fluorescence probe (a) and compared to the fluorescence for another aliquot of the platelets that were stimulated with ATP (b). Finally, inhibition of the P2X receptor with NF449 (c) suggests that the ATP receptor on the platelet is active and participates in the ability of the platelet to produce NO.

$[14,31,32]$. This mechanism, like the above mentioned, utilizes the RBC as the mediator of vascular tone, and benefits from ATP being stable in the bloodstream over the relevant time scales. Furthermore, the vasoactive form of NO is formed closer to the muscle, in the endothelium as opposed to in the RBC, so there is less diffusional travel required for the unstable molecule, and it only needs to diffuse through a single cell membrane (the endothelial cell), as opposed to through the $\mathrm{RBC}$, through the endothelial layer, and to the smooth muscle.

\section{ATP Stimulation of NO Production in the Platelet}

The primary function of platelets in the bloodstream involves hemostasis and the prevention of blood loss via clotting. Platelets normally circulate in the bloodstream without adhering to the endothelial cells lining the vessel walls however, when injury occurs and subendothelial collagen is exposed, platelets are activated. This activation is characterized by platelet shape change, which allows platelets to adhere to the vessel walls as well as recruit other circulating platelets to the growing thrombus [33, 34]. However, several other endogenous agonists also exist such as thrombin, ATP, ADP, thromboxane $\mathrm{A}_{2}\left(\mathrm{TXA}_{2}\right)$, serotonin and epinephrine, which also promote platelet activation [35]. Additionally NO, a platelet inhibitor has been widely shown to also mediate this process by activating soluble guanylate cyclase (GC) which initiates a protein kinase G (PKG) dependant pathway [36]. Bloodstream NO is not only produced by endothelial cells, but also by the platelets themselves [37].

Adenine receptors found on the platelet are major determinants in platelet function and include the $\mathrm{P}_{2} \mathrm{Y}_{1}$ and $\mathrm{P}_{2} \mathrm{Y}_{12}$ (both ADP receptors) as well as $\mathrm{P} 2 \mathrm{X}_{1}$ (ATP receptor) $[38,39]$. Both types of receptors are thought to participate in platelet aggregation, but the evidence for role of $\mathrm{P} 2 \mathrm{X}_{1}$ in aggregation is not as clear. There are reports that show $\mathrm{P} 2 \mathrm{X}_{1}$ does not function in platelet aggregation[40].

Static measurements of $\mathrm{Ca}^{2+}$ influx [41] have shown that ATP can stimulate $\mathrm{Ca}^{2+}$ influx into the platelet via the $\mathrm{P} 2 \mathrm{X}_{1}$ receptor. These increased levels of $\mathrm{Ca}^{2+}$ can elevate the concentrations of bioavailable $\mathrm{Ca}^{2+}$-calmodulin, thereby stimulating nitric oxide synthase and NO production. Fig. (2) shows NO production in platelets upon addition of ATP. Based on these reports, it would seem apparent that ATP plays a role in platelet NO production. Platelet aggregation studies have also been performed and showed increased platelet aggregation at low concentrations of ATP as well as high concentrations of ATP. It is possible that at low levels of ATP there is insufficient NO production to inhibit platelet activation, but at higher levels of ATP NOS may become saturated and the $\mathrm{Ca}^{2+}$-calmodulin complex can activate the GPIIb-IIIa complex (membrane integrin involved in platelet activation/aggregation) on the platelet membrane [42]. Both of these situations would be dependent on the amount of ATP being released by the RBC.

\section{DOES NITRIC OXIDE AFFECT THE ABILITY OF THE RBC TO RELEASE ATP?}

The evidence in the literature strongly suggests that the $\mathrm{RBC}$ has the ability to release ATP in response to such stimuli as flow-induced mechanical deformation [43], hypoxia [28, 29], acidosis [16], as well as various molecular reagents [44-46] whose exact mechanisms are currently incomplete. Moreover, the RBCs ability to release NO in response to hypoxia is established [47]. Interestingly, in addition to these reports describing the release of these two molecules (ATP and NO) from the RBC, there are also studies suggesting that levels of NO or NO metabolites in the RBC may directly affect this cell's ability to release ATP.

There have been reports that NO added to RBCs can increase the cell's deformability $[48,50]$. In this construct, one would then expect a resultant increase in ATP release from these cells upon exposure to deformation. In contrast, however, there are also reports $[51,52]$ suggesting that the addition of $\mathrm{NO}$ to the RBC can increase rigidity of the cell; in turn, such a decrease in deformability would be expected to reduce RBC-derived ATP upon exposure to deformation. In fact, it has been shown that the direct addition of NO to 


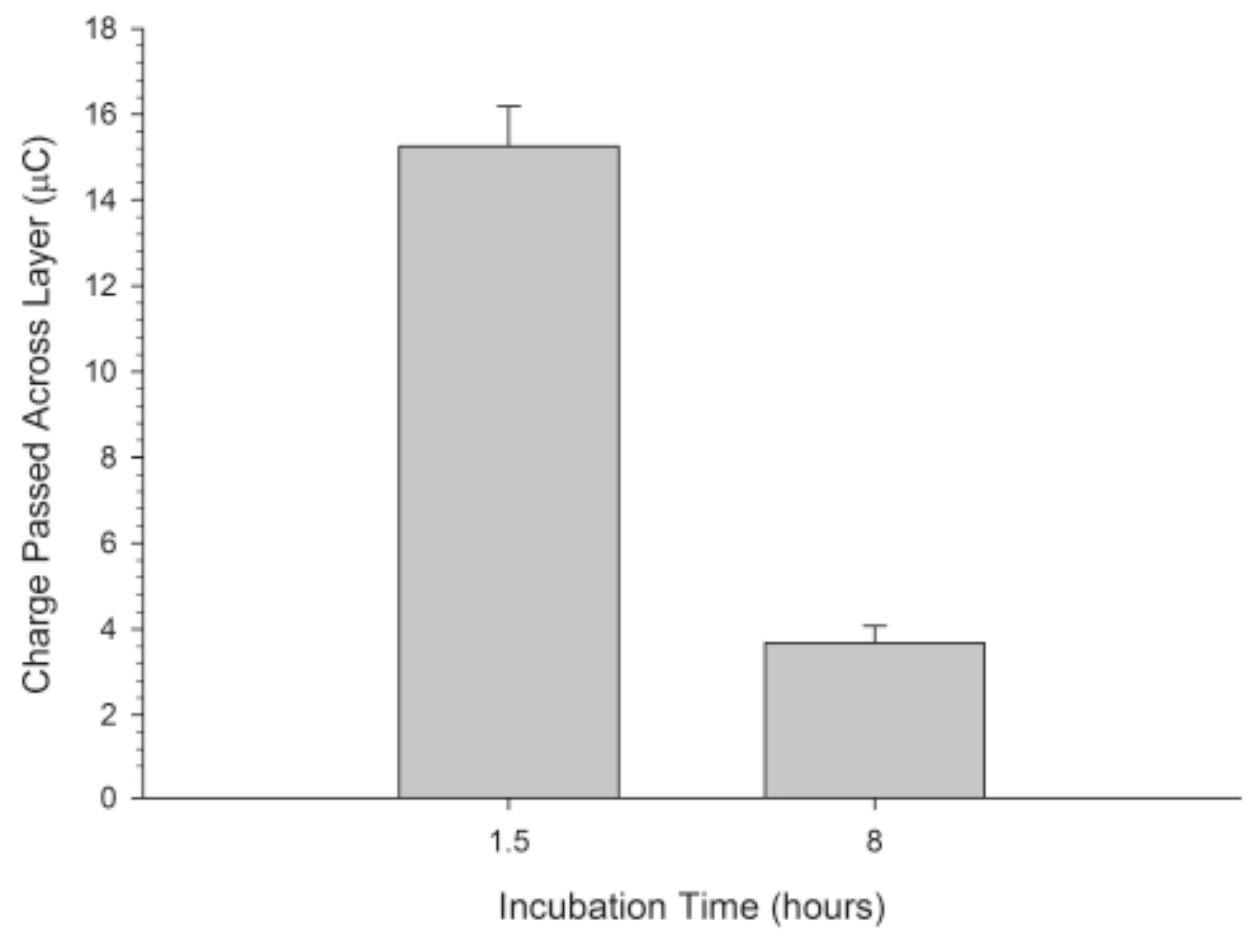

Fig. (3). Determination of Confluency of bPAEC in Microfluidic Devices. In order to determine the confluency of bPAECs in microfluidic devices, a square potential wave is applied across the cell layer, and the resulting current wave is integrated to determine charge passed across the layer. A lower charge results from a lower current, and therefore a more resistive and more confluent layer. These results suggest that proper incubation time of cell layers in devices is important.

the RBC can reduce this cell's ability to release ATP. Based on these reports, it would seem that there is inconclusive evidence regarding the effect of $\mathrm{NO}$ on ATP release from the RBC. However, a close reappraisal of these studies will reveal an interesting feature; specifically, it appears that the effect of $\mathrm{NO}$ on the $\mathrm{RBC}$ is concentration dependent.

Recently, it has been shown that either the addition of $\mathrm{NO}_{2}{ }^{-}$to RBCs results in either a decrease or increase in the ATP release from these cells [53]. It has been suggested that the addition of the nitrite to the RBCs results in the production of intracellular ATP due to an increase of activity in a membrane-bound glycolytic complex [54]. In addition to nitrite, it has also been shown that the direct addition of NO to RBCs resulted in an increase in ATP release when the cells were exposed to flow-induced deformation [55]. However, at higher levels of NO added to the RBCs the ATP release began to decrease. These studies suggest that the addition of $\mathrm{NO}$ or $\mathrm{NO}$ metabolites such as nitrite can indeed have an effect on ATP release from the RBC and, importantly, the effect seems to be dose dependent.

The above studies become important from a therapeutic point of view considering a recent study demonstrating that hydroxyurea (HU), the only proven therapy for people with sickle cell disease, seems to be stimulating eNOS in the $\mathrm{RBC}$. The production of the NO by the RBC itself was concluded to be associated with the increased release of ATP from the RBCs after a brief incubation with the HU [55]. In accordance with this report, previous studies have linked some of HU's benefits as possibly due to NO [56, 57]; however, the results demonstrating that $\mathrm{HU}$ had a direct impact on NO production by the RBC itself and that this NO was subsequently facilitating ATP release from the RBC were without precedence.

\section{ADVANCING BIOTECHNOLOGY FOR AN IMPROVED UNDERSTANDING OF THE ATP- NITRIC OXIDE RELATIONSHIP}

To determine NO activities, it is important to consider the measurement technique. Being an unstable molecule, NO can be a challenge to measure in the presence of the complex matrices inherently present in these samples. Despite these challenges, electrochemical [58], fluorescence derivatization $[32,47]$, and chemiluminescence techniques are used in NO analysis. However, in many of the investigations involving the role of RBC-derived NO, a variety of bioassays are utilized to determine vasoactivity.

In initial investigations of EDRF [2], along with Stamler's studies above [59], immobilized sections of blood vessels attached to strain gauges are utilized to determine vascular tone. While this is a valuable experimental technique because it uses tissue in its proper geometry and function, it does not offer much in the way of selectivity in terms of identifying the specific identity of active species. However, some of this selectivity can be imparted through the use of enzymatic inhibitors, such as L-NAME or LNMMA, or knockout animals [9]. Other studies performed by Gladwin's group utilize in vivo measurements of variables such as blood flow or blood pressure; however, 


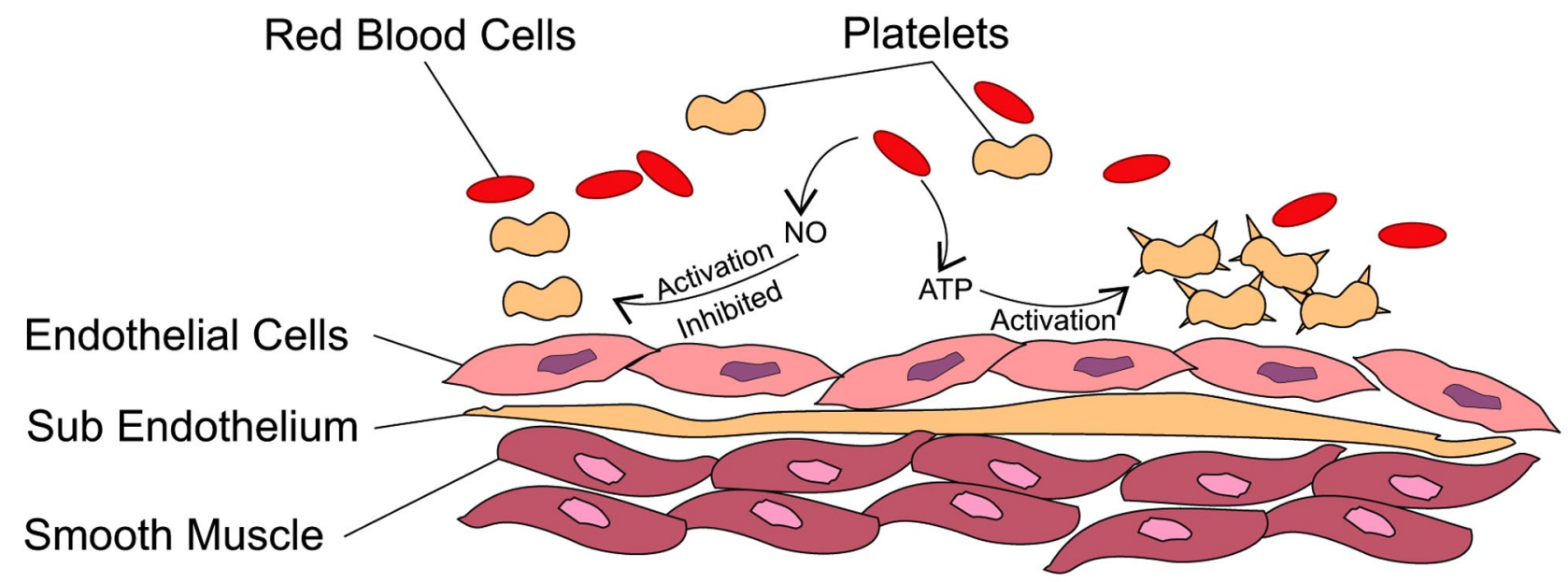

Fig. (4). Defining roles for the release of ATP and NO from the RBC. Under hypoxic conditions, the RBC is known to release both ATP and NO. While the ATP has been shown to participate in endothelial NO production, it may also have the ability to activate platelets (either through ATP or ADP activation of the platelet purinergic receptors); however, the NO that is released under hypoxic conditions would be able to inhibit the platelet activation that may occur due to the ATP release.

these methods lack the ability to specifically characterize the analytes of interest. However, these studies are still very informative due to the in vivo nature of the experiment.

To impart some selectivity to such investigations, our group utilizes microfluidic devices to simulate blood vessels. These devices offer the potential to couple most detection systems with functioning cells arranged in biologically relevant spatial locations. With these devices, we have been able to monitor RBC metabolism [60], monitor cell-cell communications including platelets, RBCs and endothelial cells $[44,61]$, and even electrochemically or through fluorescence derivatization [47, 58, 62], determine NO.

Furthermore, microfluidic systems provide improved control over the cells of interest, and offer an opportunity to monitor important variables that may affect overall results, such as endothelial layer confluence. While often considered critical for blood-brain-barrier investigations, cell confluence and the presence or absence of gaps between endothelial cells likely plays an important role in determining the levels of RBC derived NO capable of diffusing to the smooth muscle. Because the endothelial cells are cultured directly on the chip, and do not have to be removed or excised from an animal, cell layer integrity can be monitored.

Arguably, the most straightforward method for characterizing a vascular mimic is measuring transendothelial electrical resistance (TEER) across a barrier formed by a monolayer of endothelial cells. Since the cell layer restricts the movement of ions [63], TEER measurements have become the gold standard for monitoring endothelial cell monolayer integrity. The first reports of monitoring TEER across a cultured monolayer of brain endothelial cells were in 1987 [64, 65]. Since then, performing TEER measurements has become a common and simple technique and the instrumentation is now commercially available. Most of the commercially-based methods for measuring TEER across endothelial cell cultures adhered to microporous filters, or culture inserts, employ Volt-Ohm resistance meters equipped with "chopstick" electrodes, or chamber electrodes. While these instruments are capable of performing repeated fast measurements of various cell cultures with low TEER background, the same inadequacies in properly mimicking the true microvasculature that are prominent in diffusion cells also arise in these conventional TEER systems, such as a lack of shear stress and RBCs

Healthy endothelial cells form a fully confluent layer in vivo, which is also crucial to proper behavior. When an endothelial cell monolayer is prepared, it is generally characterized in one of two ways [66]: either by measuring TEER values or through the determination of permeability coefficients across the layer. As mentioned previously, these studies are generally performed using diffusion cell technology. Since the variability of models focusing on in vitro expression of the vasculature is so great, TEER measurements, or determination of permeability coefficients, should be, and often are prerequisite for publication. This stipulation should include vascular mimics involving microfluidics, which are becoming more widespread due to their ability to correct important shortcomings of the diffusion cell. Nevertheless, there are only two reports involving measuring barrier integrity across a monolayer of cells cultured on microfluidic devices $[67,68]$.

A more resistive, confluent monolayer of cells results in less total current observed as a result of decreased conductivity. Resultant data for TEER measurements performed across a monolayer of bPAECs in a microfluidic device is shown in Fig. (3); after 1 hour of growth, before confluence can be reached, and again after 8 hours after the cells have been allowed to become confluent. The use of microfluidic device technology for such measurements of cell layer integrity will increase the validity of cellular responses in vitro due to the ability to ensure endothelial cell monolayer cell confluence. Importantly, this in vivo mimic incorporates flow, thus providing another physical feature of the bloodstream that is not possible to investigate with current TEER-measurement systems. 


\section{FUTURE DIRECTIONS}

Studies involving the potential role of the $\mathrm{RBC}$ as a participant in the regulation of blood flow are not new, although there has been a significant push since the early 1990 's to explain the exact mechanism by which the RBC is a determinant. That said, there are still many questions involving the $\mathrm{RBC}, \mathrm{NO}$, and ATP that remain to be answered. For example, under hypoxic conditions, it is apparent that the RBC does release both ATP and NO. Do both of these molecules participate in smooth muscle relaxation? Or, is it possible that one of the molecules (ATP) is designed to stimulate $\mathrm{NO}$ in other tissue, such as the endothelium, while the NO derived directly from the RBC has another, very important function, namely, to inhibit platelet aggregation in the presence of such high levels of ATP being secreted by the RBC under hypoxic conditions? These possibilities are shown in Fig. (4).

Another area that will require further study is the clinical role of RBC-derived NO and ATP. Studies have shown that people with diabetes [69, 70], cystic fibrosis [43], and primary pulmonary hypertension all have RBCs that release less ATP in comparison to those RBCs harvested from the whole blood of controls. It is also known that these patient groups have hyperactive platelets, overall complications with blood flow, and, in the case of the CF patient, lower levels of NO bioavailability. The ability to modulate ATP release and NO bioavailability may prove beneficial to these groups. Studies have even been recently reported involving the importance of $\mathrm{NO}$ and the RBC in stored (banked) RBCs. In summary, while many strides have been made with respect to RBCs and NO, a complete understanding of their roles in vivo is lacking and continued efforts in this area are needed. Advances in molecular-level explanation of mechanisms and advances in biotechnological measurement schemes will facilitate this objective.

\section{ACKNOWLEDGEMENT}

None.

\section{CONFLICT OF INTERESTS}

None.

\section{REFERENCES}

[1] Furchgott, R.F.; Zawadzki, J.V. The obligatory role of endothelialcells in the relaxation of arterial smooth-muscle by acetylcholine. Nature, 1980, 288, 373-376.

[2] Ignarro, L.J.; Byrns, R.E.; Buga, G.M.; Wood, K.S. Endotheliumderived relaxing factor from pulmonary artery and vein possesses pharmacologic and chemical properties identical to those of nitric oxide radical. Circulation Res., 1987, 61, 866-879.

[3] Ignarro, L.J.; Buga, G.; Dhaudhuri, G. EDRF generation and release from perfused bovine pulmonary artery and vein. Eur. $J$. Pharmacol., 1988, 149, 79-88.

[4] Jia, L.; Bonaventura, C.; Bonaventura, J.; Stamler, J.S. Snitrosohaemoglobin: A dynamic activity of blood involved in vascular control. Nature, 1996, 380, 221-226.

[5] Gow, A.J.; Luchsinger, B.P.; Pawloski, J.R.; Singel, D.J.; Stamler, J.S. The oxyhemoglobin reaction of nitric oxide. Proc. Natl. Acad. Sci. USA, 1999, 96, 9027-9032.

[6] Kelm, M.; Feelisch, M.; Deussen, A.; Schrader, J.; Strauer, B.E. The role of nitric-oxide in the control of coronary vascular tone in relation to partial oxygen-pressure, perfusion-pressure, and flow. $J$. Cardiovasc. Pharmacol., 1991, 17, S95-S99.

[7] Kelm, M.; Schrader, J. Control of coronary vascular tone by nitricoxide. Circ. Res., 1990, 66, 1561-1575.
[8] Hakim, T.S.; Sugimori, K.; Camporesi, E.M.; Anderson, G. Halflife of nitric oxide in aqueous solutions with and without haemoglobin. Physiol. Meas., 1996, 17, 267-277.

[9] Diesen, D.L.; Hess, D.T.; Stamler, J.S. Hypoxic vasodilation by red blood cells evidence for an s-nitrosothiol-based signal. Circ. Res., 2008, 103, 545-553.

[10] Doyle, M.P.; Pickering, R.A.; DeWeert, T.M.; Hoekstra, J.W.; Pater, D. Kinetics and mechanism of the oxidation of human deoxyhemoglobin by nitrites. J. Biol. Chem., 1981, 256, 1239312398 .

[11] Gladwin, M.T.; Shelhamer, J.H.; Schechter, A.N.; Pease-Fye, M.E.; Waclawiw, M.A.; Panza, J.A.; Ognibene, F.P., Cannon, R.O. Role of circulating nitrite and s-nitrosohemoglobin in the regulation of regional blood flow in humans. Proc. Natl. Acad. Sci. USA, 2000, 97, 11482-11487.

[12] Lauer, T.; Preik, M.; Rassaf, T.; Strauer, B.E.; Deussen, A.; Feelisch, M.; Kelm, M. Plasma nitrite rather than nitrate reflects regional endothelial nitric oxide synthase activity but lacks intrinsic vasodilator action. Proc. Natl. Acad. Sci. USA, 2001, 98, 1281412819.

[13] Cosby, K.; Partovi, K.S.; Crawford, J.H.; Patel, R.P.; Reiter, C.D.; Martyr, S.; Yang, B.K.; Waclawiw, M.A.; Zalos, G.; Xu, X.L.; Huang, K.T.; Shields, H.; Kim-Shapiro, D.B.; Schechter, A.N.; Cannon, R.O.; Gladwin, M.T. Nitrite reduction to nitric oxide by deoxyhemoglobin vasodilates the human circulation. Nat. Med., 2003, 9, 1498-1505.

[14] Bogle, R.G.; Coade, S.B.; Moncada, S.; Pearson, J.D.; Mann, G.E. Bradykinin and ATP stimulate l-arginine uptake and nitric-oxide release in vascular endothelial-cells. Biochem. Biophys. Res. Conmun., 1991, 180, 926-932.

[15] Dull, R.O.; Tarbell, J.M.; Davies, P.F. Mechanisms of flowmediated signal transduction in endothelial cells: kinetics of ATP surface concentrations. J. Vasc. Res., 1992, 29, 410-419.

[16] Bergfeld, G.R.; Forrester, T. Release of ATP from human erythrocytes in response to a brief period of hypoxia and hypercapnia. Cardiovasc. Res, 1992, 26, 40-47.

[17] Miseta, A.; Bogner, P.; Berenyi, M.; Kellermayer, M.; Galambos, C.; Wheatley, D.; Cameron, I. Relationship between cellular ATP, potassium, sodium and magnesium concentrations in mammalian and avian erythrocytes. Biochem. Biophys. Acta, 1993, 1175, 133139.

[18] Sprague, R.S.; Stephenson, A.H.; Dimmitt, R. A.; Weintraub, N. A., Branch, C. A.; McMurdo, L.A.J. Effect of L-NAME on pressure-flow relationships in isolated rabbit lungs: role of red blood cells. Am. J. Physiol. Heart Circ. Physiol., 1995, 269, H1941-H1948.

[19] Sprague, R.S., Ellsworth, Mary L.; Stephenson, Alan H.; Lonigro, Andrew J. ATP: the red blood cell link to NO and local control of the pulmonary circulation. Am. J. Physiol Heart Circ. Physiol., 1996, 271, H2717-H2722.

[20] Allsup, D.J.; Boarder, M.R. Comparison of P2 purinergic receptors of aortic endothelial cell with those of adrenal medulla: evidence for heterogeneity of receptor subtype and of inositol phosphate response. Mol. Pharm., 1990, 38, 84-91.

[21] Houston, D.A.; Burnstock, G.; Vanhoutte, P.M. Different P2purinergic receptor subtypes of endothelium and smooth muscle in canine blood vessels. J. Pharmacol. Exp. Ther., 1987, 241, 501506.

[22] Liu, S.F.; McCormack, D.G.; Evans, T.W; Barnes, P.J. Characterization and distribution of P2-purinoreceptor subtypes in rat pulmonary vessels. J. Pharmacol. Exp. Ther., 1989, 251, 12041210 .

[23] Motte, S.; Perotton, S.; Boeynaems, J.M. Heterogeneity of ATP receptors in aortic endothelial cells: involvement of P2y and P2u receptors in inositol phosphate response. Circ. Res., 1993, 72, 504510.

[24] Dazel, H.H.; Westfall, D.P. Receptors for adenine nucleotides and nucleosides: subclassification, distribution and molecular characterization. Pharmacol. Rev., 1994, 46, 449-466.

[25] Kennedy, C.; Delbro, D.; Burnstock, G. P2-purinoreceptors mediate both vasodilation (via the endothelium) and vasoconstriction of the isolated reat femoral artery. Eur. J. Pharmacol., 1985, 107, 161-168.

[26] Forsberg, E.; Feuerstein, G.; Shohami, E.; Pollard, H. Adenosine triphosphate stimulates inositol phospholipid metabolism and prostacyclin formation in adrenal medullary endothelial cells by 
means of P2-purinergic receptors. Proc. Natl. Acad. Sci. USA, 1987, 84, 5630-5634.

[27] Hassessian, H.; Burnstock, G. Interacting roles of nitric oxide and ATP in the pulmonary circulation of the rat. Br. J. Pharmacol, 1995, 114, 846-850.

[28] Faris, A.; Spence, D.M. Measuring the simultaneous effects of hypoxia and deformation on ATP release from erythrocytes. Analyst, 2008, 133, 678-682.

[29] Ellsworth, M.L.; Ellis, C.G.; Goldman, D.; Stephenson, A.H.; Dietrich, H.H.; Sprague, R.S. Erythrocytes: oxygen sensors and modulators of vascular tone. Physiology, 2009, 24, 107-116.

[30] Dietrich, H.H.; Ellsworth, M. L.; Sprague, R. S.; Dacey, R. G. jr. Red blood cell regulation of microvascular tone through adenosine triphosphate. Am. J. Physiol. Heart Circ. Physiol., 2000, 278, H1294-H1298.

[31] Burnstock, G. Local-Control of blood-pressure by purines. Blood Vessels, 1987, 24, 156-160.

[32] Oblak, T.D.; Root, P.; Spence, D.M. Fluorescence monitoring of ATP-stimulated, endothelium-derived nitric oxide production in channels of a poly(dimethylsiloxane)-based microfluidic device. Anal. Chem., 2006, 78, 3193-3197.

[33] Kovacsovics, T.J.; Hartwig, J.H. Thrombin-induced GPIb-IX centralization on the platelet surface requires actin assembly and myosin II activation. Blood, 1996, 87, 618-629.

[34] Cerecedo, D.; Stock, R.; Gonzalez, S.; Reyes, E.; Mondragon, R. Modification of actin, myosin and tubulin distribution during cytoplasmic granule movements associated with platelet adhesion. Haematologica, 2002, 87, 1165-1176.

[35] Packham, M.A. Role of platelets in thrombosis and hemostasis. Can. J. Physiol. Pharm., 1994, 72, 278-284.

[36] Wang, G.-R.; Zhu, Y.; Halushka, P.V.; Lincoln, T.M.; Mendelsohn, M.E. Mechanism of platelet inhibition by nitric oxide: in vivo phosphorylation of thromboxane receptor by cyclic GMPdependent protein kinase. Proc. Natl. Acad. Sci. USA, 1998, 95, 4888-4893.

[37] Freedman, J.E.; Loscalzo, J.; Barnard, M.R.; Alpert, C.; Keaney, J.F.; Michelson, A.D. Nitric oxide released from activated platelets inhibits platelet recruitment. J. Clin. Invest., 1997, 100, 350-356.

[38] Hall, D.A.; Hourani, S.M.O. Effects of analogs of adenine nucleotides on increases in intracellular calcium mediated by P2Tpurinoceptors on human blood platelets. Br. J. Pharmacol., 1993, $108,728-733$

[39] von Kugelgen, I.; Wetter, A. Molecular pharmacology of P2Yreceptors. Naunyn-Schmiedeberg's Arch. Pharmacol., 2000, 362, 310-323.

[40] Takano, S.; Kimura, J.; Matsuoka, I.Ono, T. No requirement of P2X1 purinoceptors for platelet aggregation. Eur. J. Pharmacol., 1999, 372, 305-309.

[41] Karunarathne, W.; Ku, C.J.; Spence, D.M. The dual nature of extracellular ATP as a concentration-dependent platelet P2X1 agonist and antagonist. Integr. Biolo., 2009, 1, 655-663.

[42] Nesbitt, W.S.; Kulkarni, S.; Giuliano, S.; Goncalves, I.; Dopheide, S.M.; Yap, C.L.; Harper, I.S.; Salem, H.H.; Jackson, S.P. Distinct glycoprotein Ib/V/IX and integrin alpha(IIb)beta(3)-dependent calcium signals cooperatively regulate platelet adhesion under flow. J. Biol. Chem., 2002, 277, 2965-2972.

[43] Sprague, R.S.; Ellsworth, M.L.; Stephenson, A.H.; Kleinhenz, M.E.; Lonigro, A.J. Deformation-induced ATP release from red blood cells requires CFTR activity. Am. J. Physiol., 1998, 275, H1726-H1732.

[44] Genes, L.I.; Tolan, N.V.; Hulvey, M.K.; Martin, R.S.Spence, D.M. Addressing a vascular endothelium array with blood components using underlying microfluidic channels. Lab. Chip., 2007, 7, 12561259.

[45] Meyer, J.A.; Froelic, J.M.; Reid, G.E.; Karunarathne, W.; Spence, D.M. Metal-activated C-peptide facilitates glucose clearance and the release of a nitric oxide stimulus via the glut1 transporter. Diabetologia, 2008, 51, 175-182.

[46] Meyer, J.A.; Subasinghe, W.; Sima Anders, A.F.; Keltner, Z.; Reid, G.E.; Daleke, D.L.; Spence, D.M. Zinc-activated c-peptide resistance to the type 2 Diabetic erythrocyte is associated with hyperglycemia-induced phosphatidylserine externalization and reversed by metformin. Mol. Biosyst., 2009, 5, 1157-1162.

[47] Halpin, S.T.Spence, D.M. Direct plate-reader measurement of nitric oxide released from hypoxic erythrocytes flowing through a microfluidic device. Anal. Chem., 2010, 82, 7492-7497.
[48] Bor-Kucukatay, M.; Wenby, R.B.; Meiselman, H.J.; Baskurt, O.K. Effects of nitric oxide on red blood cell deformability. Am. J. Physiol. Heart Circ. Physiol., 2003, 284, H1577-H1584.

[49] Korbut, R.A.; Adamek-Guzik, T.; Madej, J.; Korbut, R. Endothelial secretogogues and deformability of erythrocytes. J. Physiol. Pharmacol., 2002, 53, 655-665.

[50] Starzyk, D.; Korbut, R.; Gryglewski, R.J. Effects of nitric oxide and prostacyclin on deformability and aggregability of red blood cells of rats ex vivo and in vitro. J. Physiol. Pharmacol., 1999, 50, 629-37.

[51] Bateman, R.M.; Jagger, J.E.; Sharpe, M.D.; Ellsworth, M.L.; Mehta, S.; Ellis, C.G. Erythrocyte deformability is a nitric oxidemediated factor in decreased capillary density during sepsis. Am. J. Physiol. Heart. Circ. Physiol., 2001, 280, H2848-H2856.

[52] Mesquita, R.; Picarra, B.; Saldanha, C.; Silva, J.M.E. Nitric oxide effects on human erythrocytes structural and functional properties An in vitro study. Clin. Hemorheo. Micro., 2002, 27, 137-147.

[53] Garcia, J.I.; Seabra, A.B.; Kennedy, R.; English, A.M. Nitrite and nitroglycerin induce rapid release of the vasodilator ATP from erythrocytes: Relevance to the chemical physiology of local vasodilation. J. Inorg. Biochem., 2010, 104, 289-296.

[54] Cao, Z.; Bell, J.B.; Mohanty, J.G.; Nagababu, E.; Rifkind, J.M. Nitrite enhances RBC hypoxic ATP synthesis and the release of ATP into the vasculature: a new mechanism for nitrite-induced vasodilation. Am J. Physiol Heart Circ Physiol, 2009, 297, H1494H503.

[55] Raththagala, M.; Karunarathne, W.; Kryziniak, M.; McCracken, J.; Spence, D.M. Hydroxyurea stimulates the release of ATP from rabbit erythrocytes through an increase in calcium and nitric oxide production. Eur. J. Pharmacol., 2010, 645, 32-38.

[56] Gladwin, M.T.; Schechter, A.N.; Ognibene, F.P.; Coles, W.A.; Reiter, C.D.; Schenke, W.H.; Csako, G.; Waclawiw, M.A.; Panza, J.A.; Cannon, R.O. Divergent nitric oxide bioavailability in men and women with sickle cell disease. Circulation, 2003, 107, 271278 .

[57] King, S.B. The nitric oxide producing reactions of hydroxyurea. Curr. Med. Chem., 2003, 10, 437-452.

[58] Hulvey, M.K.; Martin, R.S. A microchip-based endothelium mimic utilizing open reservoirs for cell immobilization and integrated carbon ink microelectrodes for detection. Anal. Bioanal. Chem. 2009, 393, 599-605.

[59] Stamler, J.S.; Jia, L.; Eu, J.P.; McMahon, T.J.; Demchenko, I.T.; Bonaventura, J.; Gernert, K.; Piantadosi, C.A. Blood flow regulation by $\mathrm{S}$-nitrosohemoglobin in the physiological oxygen gradient. Science, 1997, 276, 2034-2037.

[60] Tolan, N.V.; Genes, L.I.; Subasinghe, W.; Raththagala, M.; Spence, D.M. Personalized metabolic assessment of erythrocytes using microfluidic delivery to an array of luminescent wells. Anal. Chem., 2009, 81, 3102-3108.

[61] Ku, C.J.; Oblak, T.D.; Spence, D.M. Interactions between multiple cell types in parallel microfluidic channels: Monitoring platelet adhesion to an endothelium in the presence of an anti-adhesion drug. Anal. Chem., 2008, 80, 7543-7548.

[62] Letourneau, S.; Hernandez, L.; Faris, A.N.; Spence, D.M. Evaluating the effects of estradiol on endothelial nitric oxide stimulated by erythrocyte-derived ATP using a microfluidic approach. Anal. Bioanal. Chem., 2010; 397(8):3369-3375.

[63] Butt, A.M.; Jones, H.C.; Abbott, N.J. Electrical resistance across the blood-brain barrier in anaesthetized rats: a developmental study. J. Physiol., 1990, 429, 47-62.

[64] Hart, M.N.; VanDyk, L.F.; Moore, S.A.; Shasby, D.M.; Cancilla, P.A. Differential opening of the brain endothelial barrier following neutralization of the endothelial luminal anionic charge in vitro. $J$. Neuropathol. Exp. Neurol., 1987, 46, 141-153.

[65] Rutten, M.J.; Hoover, R.L.; Karnovsky, M.J. Electrical resistance and macromolecular permeability of brain endothelial monolayer cultures. Brain Res., 1987, 425, 301-310.

[66] Deli, M.A.; Abraham, C.S.; Kataoka, Y.; Niwa, M. Permeability studies on in vitro blood-brain barrier models: Physiology, pathology, pharmacol. Cell. Mol. Neurobiol., 2005, 25, 59-127.

[67] Young, E.W.K.; Watson, M.W.L.; Srigunapalan, S.; Wheeler, A.R.; Simmons, C.A. Technique for real-time measurements of endothelial permeability in a microfluidic membrane chip using laser-induced fluorescence detection. Anal. Chem., 2010, 82(3), 808-816. 
[68] Douville, N.J.; Tung, Y.-C.; Li, R.; Wang, J.D.; El-Sayed, M.E.H.; Takayama, S. Fabrication of two-layered channel system with embedded electrodes to measure resistance across epithelial and endothelial barriers. Anal. Chem.2010, 82, 2505-2511.

[69] Carroll, J.; Raththagala, M.; Subasinghe, W.; Baguzis, S.; Oblak, T.D.A.; Root, P.; Spence, D. An altered oxidant defense system in red blood cells affects their ability to release nitric oxidestimulating ATP. Mol. BioSyst., 2006, 2, 305-311.

[70] Sprague, R.S.; Stephenson, A.H.; Bowles, E.A.; Stumpf, M.S.; Lonigro, A.J. Reduced expression of Gi in erythrocytes of humans with type 2 diabetes is associated with impairment of both cAMP generation and ATP release. Diabetes, 2006, 55, 3588-3593.

(C) Halpin et al.; Licensee Bentham Open.

This is an open access article licensed under the terms of the Creative Commons Attribution Non-Commercial License (http://creativecommons.org/licenses/by-nc/3.0/) which permits unrestricted, non-commercial use, distribution and reproduction in any medium, provided the work is properly cited. 